\title{
Historia, poesía y cotilleos. Cristina de Suecia en los Avisos de Barrionuevo
}

\author{
History, Poetry and Gossip. Cristina of Sweden \\ in the Avisos of Barrionuevo
}

\author{
Ignacio Arellano \\ Universidad de Navarra
}

\section{RESUMEN}

El artículo examina el modo en que aparece la figura de la reina Cristina de Suecia en los Avisos o noticias de Jerónimo de Barrionuevo, que va comentando los sucesos contemporáneos desde una perspectiva que podríamos llamar satírica, y que se relaciona con las convenciones propias del mismo género, pero también con la actitud intelectual y política del narrador.

De este modo se advierte que ciertos motivos se reservan para ciertos géneros: en este caso los chismes y cotilleos que no suelen aparecer en tratamientos propiamente literarios, forman el núcleo de los textos que definen en Barrionuevo la principal perspectiva con la que se evoca a Cristina. Así pues, no solo las prerrogativas de la poesía permiten modelar el tratamiento de los personajes históricos acudiendo a alteraciones de los hechos legitimadas por las teorías poéticas de la época; también los privilegios libérrimos del cotilleo adquieren un protagonismo especial, con un marcado predominio en Barrionuevo de la mirada misógina - que podría ser propia del relator o debida a la tendencia satírica de la misma categoría textual-.

Palabras Clave: Historia; Poesía; Cristina de Suecia; Avisos de Barrionuevo.

\section{ABSTRACT}

The article examines the way in which appears the figure of Queen Christina of Sweden in notices or news of Jerónimo Barrionuevo, who is commenting on contemporary events from a perspective that might consider satirical, and that relates to the conventions of the literary gender, but also with the intellectual and political attitude of the narrator.

It is observed that in the dichotomy between real person and character built by the text, some kind of news that spread as gossip, are excluded from the literary treatments of Christina of Sweden, while define the perspective of Barrionuevo. In this case, not only the prerogatives of poetry define the treatment of historical characters; the whispering privileges acquired a special role, linked also with a misogynist perspective of the relator and tendencies of satirical categories.

Key words: History; Poetry; Christina of Sweden; Avisos of Barrionuevo. 
Persona y personaje: dos conceptos que se contraponen, coinciden en diversa medida, o se complementan en buena parte en el momento de construir el perfil de un individuo histórico. Digo «construir» porque toda descripción es en gran medida un modo de enfoque, un punto de vista marcado por múltiples intereses.

La relación del discurso histórico y del discurso poético con la «realidad» implica cuestiones mucho más complejas de las que superficialmente se aparecen al lector ingenuo. El historiador, por más positivista y objetivo que pretenda ser — cosa que a menudo ni pretende-, difícilmente escapará a numerosas instancias de distinto nivel, que orientan la «construcción de la realidad» descrita en su relato. Certeramente apunta R. Lauer (1992: 26), que la historia no es «inocente» a la hora de presentar los hechos. Ni la Historia ni la Poesía, entonces, renuncian a (o se libran de, según quiera enfocarse la cuestión) un elemento de creación más o menos ficcional.

Hay alguna diferencia: el historiador pretende sin duda convencer a su receptor de que ofrece una visión «real», justa y verdadera en lo posible, hágalo con sinceridad o con intenciones conscientes de manipulación ideológica. El poeta aurisecular, en cambio, nunca pretende tal cosa. Con total libertad, sin disimulo alguno, ofrece una construcción artística, cuyo material de base puede ser la Historia, pero cuyos límites libérrimos los pone la Poesía.

Aristóteles proporciona la base teórica:

No corresponde al poeta decir lo que ha sucedido, sino lo que podría suceder, esto es, lo posible según la verosimilitud [...] Por eso también la poesía es más filosófica y elevada que la historia, pues la poesía dice más bien lo general y la historia lo particular (Poética, 1451a38-1451b7).

Cualquier rastreo de las preceptivas del Siglo de Oro permite reconocer las concepciones aristotélicas, vertidas unas veces hacia la defensa de los objetivos didácticos (cumplidos mejor con temas instructivos como los de la historia), y dirigidas otras (sobre todo en las preceptivas escritas por dramaturgos practicantes) hacia la defensa de la libertad creadora del poeta frente a los datos históricos que forman la materia prima. Alonso López Pinciano en su Filosofía Antigua Poética escribe que «mucho más excelente es la poesía que la historia [...] porque el poeta es inventor [...] Los poemas que sobre historia toman su fundamento son como una tela cuya urdimbre es la historia, y la trama es la imitación y la fábula. Este hilo de trama va con la historia tejiendo su tela, y es de tal modo que el poeta puede tomar de la historia lo que se le antojare y dejar lo que le pareciere» (epístolas IV y V), y en otro lugar abunda con claridad meridiana: «El poeta no se obliga a escribir verdad, sino verisimilitud, quiero decir posibilidad en la obra [...] y al poeta lícito le es alterar la historia». Y así podríamos revisar otras preceptivas como las de Luis Alfonso de Carvallo, Cisne de Apolo, o las Tablas poéticas de Francisco Cascales. Y Tirso de Molina, defendiendo las libertades de El vergonzoso en pa- 
lacio, hace decir a un su portavoz, en pasaje muy conocido, que merece la pena citar una vez más:

Pedante hubo historial que afirmó merecer castigo el poeta que contra la verdad de los anales portugueses, había hecho pastor al duque de Coimbra, don Pedro, siendo así que murió en una batalla que el rey don Alonso, su sobrino, le dio, sin que le quedase hijo sucesor-, en ofensa de la casa de Avero y su gran duque, cuyas hijas pintó tan desenvueltas, que contra las leyes de su honestidad, hicieron teatro de su poco recato la inmunidad de su jardín. ¡Como si la licencia de Apolo se estrechase a la recolección histórica y no pudiese fabricar, sobre cimientos de personas verdaderas arquitecturas del ingenio fingidas!

Pero la distinción entre Historia y Poesía no es tan clara como los preceptistas señalan. En sustancia podríamos decir que el historiador se comporta a menudo como un poeta, en cuanto su visión de la persona desemboca en la creación de un personaje.

Cuando un individuo histórico se convierte en protagonista literario el poeta lo maneja libremente, y lo mismo hace, con más escrúpulos aparentes y asegurando una fidelidad que no puede ser nunca total, el historiador.

$\mathrm{Y}$ en este marco se producen algunos casos de particular interés: tal el de la reina Cristina de Suecia, cuya trayectoria vital, por lo que sabemos, fue en buena medida un intento de ella misma — persona histórica- de convertirse en un mito o personaje heroico, digno de pasar a la historia o mejor aún de pasar a las historias. En este sentido resulta difícil desbrozar qué es lo que pertenece a la realidad empírica, factual, y qué corresponde a esa creación del mito de la Minerva del norte, la Diana de la Europa moderna ${ }^{1}$, con su secuela de admiraciones, escándalos, elogios y calumnias que surgen en torno a Cristina Alejandra Adolfo de Suecia, caso privilegiado para abordar algunas de estas cuestiones ${ }^{2}$.

Resulta significativa la ponderación que don Baltasar Mercader, castellano de Amberes, escribe a su hermano, a propósito de algunos sucesos relativos a Cristina, a los que compara con las trazas de una comedia: «Parecen cosas de comedia las que estoy viendo... Es una comedia y todo lo que está sucediendo lo parece»(Clavería, 1952: 19).

Cristina, que tan famosa se haría en las cortes europeas del XVII, tiene ya un nacimiento prodigioso, casi teriomorfo, como tantos protagonistas teatrales (Segismundo mismo de La vida es sueño o Semíramis de La hija del aire

${ }^{1}$ Para la importancia de estos modelos de Minerva o Diana en la construcción del personaje, véase Allendesalazar (2009: 104) y López Cordón (2004). Interesantes detalles sobre la iconografía de Cristina como Minerva y Diana en Mancini (2003).

${ }^{2}$ Compte examina algunos aspectos de la reina Cristina, a quien considera «The most fascinating and oft-mentioned female personage in the Avisos» (2012: 204), que compara en ocasiones con el tratamiento que hace Barrionuevo de la reina Mariana de Austria. Se pueden completar algunos aspectos que aquí comento con la aproximación de Compte. 
de Calderón), aunque no aciago: viene al mundo (el 8 de diciembre de 1626) envuelta en una especie de manto, con abundante vello y dando «extraordinario e imperioso rugido» ${ }^{3}$, por lo cual la confunden en un principio con un varón.

El 7 de diciembre de 1644 presta juramento y asume el gobierno de Suecia, mostrando gran interés en las tareas políticas, y sobre todo en diseñar para sí misma una personalidad heroica y original, digna de la dimensión de una leyenda.

Reina varonil, enemiga del matrimonio, celosa de la propia libertad, estudiosa pertinaz, aficionada a la filosofía, gran caballista, poseedora de varias lenguas, se convierte en la admiración de toda Europa, cuyo pasmo crece al abdicar el 6 de junio de 1654, y convertirse luego al catolicismo: abjura del protestantismo en Innsbruck el 3 de noviembre de 1655 y recibe la confirmación el 23 de diciembre, en una fastuosa ceremonia, acompañada de fiestas, desfiles triunfales y grandes celebraciones. En pocos años, como señala Mancini (2003: 242), la reina se convertirá en «uno de los protagonistas absolutos de la vida cultural romana».

Los retratos que la mayoría de testigos o implicados en estos sucesos ofrecen evocan un personaje extraordinario. El padre Mannerschied, confesor del embajador Pimentel, subraya las cualidades admirables de Cristina:

Sabe diez u once lenguas [...] Lo mismo es de los poetas antiguos, porque los lee y sabe excelentemente. Los suecos, franceses y italianos los sabe de memoria. Todos los filósofos antiguos los ha leído, como también muchísimo de los santos padres [...] Tiene memoria más que humana. Parece saberlo todo, que no se olvida de nada y que no ignora nada (cit. por Clavería, 1952: 18).

El residente francés, Chanut, en diversos informes y cartas, la describe como buena cristiana, muy capaz de ir al fondo de los asuntos, aficionada a vestir de hombre, amazona excelente, ansiosa de nuevos conocimientos, aunque le parece excesiva la obsesión de la reina por aprender:

lo que no puedo aprobar es que esta princesa que domina el latín, el francés, el flamenco, el alemán y el sueco, se dedique ahora a estudiar griego (Allendesalazar, 2009: 124 y 126).

De todos modos, quizá por inclinación diplomática, destaca que todas las cualidades de la reina palidecen «ante su pasión por el honor y la virtud; se podría decir que su ambición le empuja a hacerse célebre ella misma por su extraordinarios méritos [...] Prefiere que su reputación se base en sus méritos personales y no dependa del valor que demuestren sus súbditos».

Ya al abandonar Suecia en su camino hacia Roma, vestida de hombre, como un personaje de novela o de comedia, empieza una nueva etapa en su vida, más compleja y ambigua. Allendesalazar escribe:

\footnotetext{
${ }^{3}$ Lo comenta ella misma en su autobiografía; véase Allendesalazar (2009: 19).
} 
Cristina tenía ya el carácter de los personajes de leyenda. Ya se había transformado en la magnífica leyenda viva de la Minerva del Norte y de la Reina Filósofa. Ahora con sus viajes, sus aventuras e intrigas iba a crear una nueva leyenda. Pero esta ya no iba a ser tan elogiosa... (2009: 237).

En lo que a España se refiere la conversión al catolicismo de Cristina la convierte en figura protagonista de noticias, poemas, obras de teatro, relaciones y ¿cómo no?, murmuraciones y rumores.

De los poemas que se le dedican destacan los de Bernardino de Rebolledo, embajador en Dinamarca, quien le ofrece el libro La constancia victoriosa. Égloga sacra (1655), y otras composiciones como el soneto «Arde el Báltico mar, cuyos cristales», donde la compara con Minerva y Venus ${ }^{4}$ :

Arde el Báltico mar, cuyos cristales,
luminosos reflejos dan al suelo
desde que aposentaron en su hielo
de Cristina las luces celestiales.
Pervertidos los términos fatales,
del uno al otro opuesto paralelo
incluyó breve golfo tanto cielo
en asombro común de los mortales.
Y lustradas de puros esplendores
brotan de Tetis las cavernas hondas
de perlas rica numerosa suma,
y ceñido de cándidos fulgores
vuelve a nacer el sol entre las ondas
y Minerva, cual Venus, de la espuma.

De las obras de teatro las más notables son Afectos de odio y amor y La protestación de la fe (comedia y auto de Calderón), y ¿Quién es quien premia al amor?, comedia de Bances Candamo.

No voy ahora a repasar estas piezas, que han recibido ya atención de la crítica (Clavería, 1952; Prieto, 1978-1980; Maler, 1978; Mackenzie, 1979; Weiner, 1979; Lundelius, 1986; Oostendorp, 1989; Vásquez Lopera, 1998; Andrachuck, 2001; Escalonilla, 2005; Oteiza, 2009; Zúñiga, 2012). Me limitaré a observar que se suele considerar Afectos de odio y amor como la más

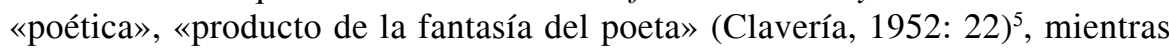
que ¿Quién es quien premia al amor? se atiene en buena parte a la realidad histórica, y maneja fuentes concretas, al menos los Ocios de Bernardino de Rebolledo: la carta de la reina a don Luis de Haro reproduce el texto de una

\footnotetext{
${ }^{4}$ Para las relaciones de Cristina y Rebolledo, y para las poesías de este ver González Cañal (1986) y su Edición crítica de los «Ocios» del Conde de Rebolledo (1997).

${ }^{5}$ Para Oostendorp (1989: 250), en esta comedia «los datos históricos son usados ahora como elementos de un mundo fantástico en que reina el ambiente de las novelas caballerescas», etc.
} 
carta auténtica publicada por Rebolledo en sus obras poéticas (Amberes, 1660), y los principales protagonistas (don Antonio Pimentel, Carlos Gustavo de Suecia, el duque de Holstein...) tienen modelos históricos reales. Pero sobre la documentación histórica el poeta ejerce su libertad de creación: como apuntan Oostendorp o Suárez (Oostendorp, 1989: 254 y ss.; Suárez, 1992: 44) las relaciones de Cristina con España no eran exactamente como las pinta Bances y la sucesión cronológica (y causal) de los hechos históricos representados ha sido alterada en beneficio de la organización poética del drama.

Al comparar Mackenzie (1979) esta comedia con el auto de La protestación de la fe, halla que Calderón presenta un personaje más cercano a la realidad histórica, más varonil, mientras que Bances Candamo, ceñido «en exceso» al concepto dramático del decoro, presenta un personaje mucho más femenino y cortesano. En realidad lo que sucede es que en este caso Bances ha concebido la obra como una comedia de fábrica más que historial ${ }^{6}$, lo que favorece el vuelo poético de la ficción.

Pero es hora de dejar el terreno más literario y pasar a los textos noticiosos de Jerónimo Barrionuevo, que es para Weiner «el mayor cronista de ella en España» (1979: 26).

Antes de seguir conviene recordar unos detalles elementales sobre este corpus de Avisos que constituyen la materia de observación de las páginas siguientes.

Los Avisos pertenecen a un género de escritos de (para)literatura pragmática, cuya fidelidad a la realidad coetánea que describen es más estrecha que la que generalmente muestran los textos de ficción. No son tampoco un reflejo exacto: toman sus datos a la realidad, pero proponen sobre ellos una reflexión que depende de la propia perspectiva y de la que se desprende una imagen que implica un cierto grado de compromiso.

El objetivo primordial de Barrionuevo es claro: este clérigo, tesorero de Sigüenza, y vecino de Madrid en los años de 1654 a 1658, pretende dar noticia a otro clérigo de Zaragoza, amigo suyo, de los sucesos que se comentan y producen en la corte.

La colección de cartas de los años 1654-1658 que constituyen estos Avisos es una muestra importante de la literatura de gacetas y noticiarios que se extiende por el Siglo de Oro. No se encuentra en Barrionuevo una serie sistemática ni completa de observaciones: sus comentarios están limitados por el ámbito político y cortesano, por el mismo estilo noticioso (informaciones breves y glosas o apostillas concisas, sin desarrollo de reflexiones sistemáticas), y por la reducción a los hechos bélicos y políticos que margina otros aspectos: de ahí que a menudo la atención prestada a personajes concretos sea lo principal.

\footnotetext{
${ }^{6}$ Para estos géneros ver Arellano (1998).
} 
Hay tres personajes que solicitan muy intensamente la atención de Barrionuevo: Cromwell, el duque de Lorena, y quien ahora me interesa, la reina Cristina de Suecia, a quien dedica comentarios en 62 cartas $^{7}$.

Según Weiner, que es quien más se ha fijado en los Avisos, Barrionuevo muestra una actitud casi siempre entusiasta hacia Cristina, apreciación que había ya defendido Clavería (Weiner, 1979: 27; Clavería, 1952: 20) ${ }^{8}$, quien califica la décima que se incluye en el aviso de 11 de marzo de 1656, de «fruto espontáneo de su entusiasmo», en ocasión de la entrada triunfal de Cristina en Roma. La décima, bastante mala, es esta:

\author{
Sea Dios ensalzado; \\ la gloria cante su Iglesia \\ de la reina de Suecia \\ en Roma la regia entrada; \\ la herejía depravada \\ holló, abjuró, detestó; \\ a Pedro reconoció, \\ como yo, por vice Cristo. \\ Triunfo mayor no se ha visto: \\ vino, entró, venció, triunfó (I: 253).
}

Pero no bastan los versos; hay que añadir los comentarios, y colocarlos además en su contexto: Barrionuevo envía una relación de la entrada de Roma, y se le ocurre añadir de su cosecha la décima en cuestión:

\begin{abstract}
Remito a vm. esa relación de la entrada en Roma de la reina de Suecia; es cosa grande y se espera por este medio la reducción de muchas cabezas grandes y el remedio de infinitas almas. Hágalo Dios, que puede. Espérase vendrá muy presto también por acá, donde se dice se preparan en Madrid grandes fiestas con que festejarla [...] De mi parte la he festejado con esta décima. Cada uno ofrece lo que puede [...] Parece que estoy de buen humor (I: 253).
\end{abstract}

En sustancia la décima parece más bien un comentario distanciado algo humorísticamente, según marcan los incisos del discurso («Hágalo Dios, que puede», «parece que estoy de buen humor, que no es poco») de la fastuosa entrada, que una muestra de genuino entusiasmo.

Semejante interpretación puede apoyarse en otros avisos en los que comenta los regalos y celebraciones, y en algunos más donde es evidente la postura crítica ante semejantes gastos. Varias veces se refiere a los presentes que $\mathrm{Fe}$ lipe IV envía a la reina y a los preparativos de comedias y fiestas de toros y cañas:

\footnotetext{
${ }^{7}$ Se pueden localizar en el índice del volumen (Barrionuevo, 1968, II: 318). Citaré los avisos por la edición de Paz y Mélia en la BAE, tomo y página. Algunas aportan noticias neutras sobre los viajes, devociones y otras peripecias de la reina que se anuncian de paso (I: 109, 234, 239, 247; II: 186, etc).

${ }^{8}$ También Compte (2012: 204), considera este poema eminentemente panegírico.
} 
Su majestad le envía ahora 30 caballos hermosísimos y ricamente aderezados, muchas cosas ricas de las Indias, y la reina muchas cosas de olor. (I: 58) [...] La reina de Suecia viene a Madrid, de cierto, antes de Navidad, donde se dice se previenen muchas fiestas de toros y cañas, máscaras y sortijas para festejarla (I: 64) [...] Su Majestad envía a la reina de Suecia 24 caballos, cosa valiente, y un grandísimo número y copia de todos los libros jocosos y de buen gusto, así en prosa como en verso... (I: 81) [...] Para la venida de esta reina de Suecia [...] se envía a Italia por otros tramoyistas, fuera del Bacho [...] porque quieren los reyes agasajarla mucho y tenerle muchas fiestas... (I: 250).

No parece que a Barrionuevo puedan entusiasmar tales dispendios. Póngase en relación la noticia sobre la comedia de tramoyas que recoge el 3 de febrero de 1655, con los comentarios sobre los derroches superfluos con característicos de los Avisos:

A 8 de abril es la comedia del Retiro de tantas tramoyas, y que se dilata para que sea uno de los festejos de la reina de Suecia, entre otros muchos que se han de hacer de toros, cañas, máscaras y sortijas. Veremos, si vivimos, en lo que para (I: $108)$.

¿Qué piensa Barrionuevo de estos festejos? Una sola muestra (12 de enero 1656 , sobre otra comedia de tramoyas):

La comedia de tramoyas se hace para carnestolendas. Es cosa grande. Paga el gasto el marqués de Liche y para acabar de perfeccionarla le pide el que la hace 30000 ducados. Es cosa cierta. Si yo los tuviera los empleara mejor (I: 237).

La seriación de noticias no es tampoco inocente, creo, en otros casos: nótese en la carta de 20 de marzo de 1665 cómo dispone sus comentarios: primero sobre la caza del rey - especialmente el coste exorbitante de la diversión-, y acto seguido los regalos que se hacen a Cristina de Suecia, que quedan inevitablemente contaminados por el significado del derroche que se acaba de criticar:

Mató el rey un lobo muy grande el otro día y costole de cebar para que viniese a sus manos 18000 reales [...] Han ido muchos a verle, entre ellos un patriarca que dijo: «Aquí falta poner: «Costó esta muerte 18000 reales»». El miércoles vino el rey del Escorial, de otra caza, donde se dice ha gastado 30000 reales [...] Otro presente de caballos de campo, haca, cosas de ámbar y de la India envía ahora el rey a la reina de Suecia, de quien está muy pagado (I: 118).

No olvida consignar el pasquín que sale en Roma criticando los gastos hechos para la entrada de la reina mientas había falta de pan (I: 293).

Es cierto que hay algunos elogios a Cristina, sobre todo en el primer momento en el que parece que su conversión la acerca al rey de España, como su padrino y protector, pero es difícil advertir el entusiasmo que algunos estudiosos han visto. El 8 de enero de 1656 da noticia de la abjuración de la reina en Inspur (Innsbruck), sin mayor exaltación (I: 235), y solo se puede locali- 
zar un pasaje en el que retoma los habituales detalles panegíricos del retrato de Cristina al comentar precisamente el cuadro que le ha enviado a Felipe IV:

está armada, de medio cuerpo arriba, gallardísimo el talle, hermosa cara, ojos vivos y rasgados, y con tal severidad que dice bien lo que es. Sabe el arte militar tan bien como el general más experto. Es apacible y cuerda; habla 11 lenguas; estudiosísima en todas ciencias, y tan viva y presta que con ser un azogue es toda un oro... (I: 237).

Lo más frecuente es cierto escepticismo: «Hágalo Dios», «Todo lo puede hacer Dios» apostilla sistemáticamente, como si no pudiera fiarse mucho de los propósitos humanos: una de las primeras noticias (2 septiembre 1654) comenta:

La reina de Suecia ha escrito al Pontífice; quiere venir a Bolonia a disputar de la religión, y que si fuese convencida, reducirá todo su reino. Todo lo puede hacer Dios (I: 55).

Evidentemente no tiene intención de convertir a todo su reino: un año después de la anotación transcrita, Barrionuevo considera la famosa conversión cosa de más ruido que nueces:

La reina de Suecia [...] va a volverse católica [...] Si lo hubiera hecho antes de dejar el reino hubiera acertado, pues con esto pudiera ser se hubieran reducido aquellas gentes al verdadero conocimiento de la religión cristiana. Debe esto, sin duda, de convenir, pues así Dios lo permite (I: 210).

Es característica de los Avisos relativos a Cristina, la marcada inclinación al comentario cuando menos poco respetuoso y burlón sobre la agitación de esta mujer a la que Barrionuevo considera sin duda de cascos ligeros («un azogue»). El distanciamiento jocoso se evidencia ${ }^{9}$, por ejemplo, en varias categorías de alusiones chistosas, por ejemplo a posibles deseos de tener un hijo de Felipe IV:

La reina de Suecia ha escrito al rey una elegantísima carta [...] Pídele le señale en Italia algún lugar ameno y de recreación, donde dicen quiere retirarse [...] Solo le falta que se le antoje le haga algún hijo el rey, que en esto de bastardos tiene muy buena mano, y en los legítimos una dicha muy corta (I: 211).

Mucho se parece el modo de esta reina a la de Saba [...] Mire no se le antoje lo que a la otra, que el rey es para todo y la cumplirá (I: 244).

La devoción católica de la reina no le parece tampoco cosa muy sólida. Es difícil que Barrionuevo se tomara en serio los rumores de que Cristina pensaba hacerse monja en el convento de las Descalzas de Madrid (I: 273),

\footnotetext{
${ }^{9}$ Weiner parece tomar en serio estos comentarios de Barrionuevo, que a mí me parecen claramente burlones: «Hasta el rompimiento entre Cristina y España Barrionuevo avisa de que Cristina llevará a su país y a los países vecinos al catolicismo. Además declara que Cristina va a venir a España para vivir en un convento madrileño, y en varias ocasiones insinúa alguna relación íntima entre la sueca y Felipe IV» (1979: 27).
} 
como por otra parte evidencia el pasaje que titula «Varios desvaríos y pronóstico incierto sobre los nuevos duendes del Buen Retiro» (7 de junio de 1656): ahí comenta la presencia misteriosa de unos personajes en el Buen Retiro, que nadie sabe quiénes son y que provocan las cábalas de la gente: unos dicen que Cromwell, otros que el rey don Sebastián de los portugueses, otros el embajador del Turco, el nuncio del Preste Juan, pero las monjas «saben ya que es la reina de Suecia, que viene a fundar religión de mujeres desengañadas» (I: 284): personaje ya de caricatura, duendecillo, fábula del vulgo, la reina se ha convertido para Barrionuevo en una figura entre satírica y jocosa.

Más allá de estas bromas Barrionuevo evoca en otras ocasiones un personaje ambiguo, cuyas relaciones con España pronto se enturbian, y se pueblan de rumores de conspiraciones, conjuras y hasta traiciones. Ya se había hecho eco en varias cartas de distintas actividades políticas de Cristina, vistas con recelo y consideradas inoportunas por el relator: pretensiones de hacer las paces entre Francia y España «cosa que parece no tiene fundamento» (I: 114), o consejos no solicitados al papa, que le responde «algo acedo» (I: 269), etc.

En cualquier caso, parece que Cristina esperaba que Felipe IV la hiciese gobernadora de Flandes o Nápoles, y al no producirse este nombramiento, se inclina a ofrecerse a Francia para invadir Nápoles con la ayuda de Mazarino ${ }^{10}$. Barrionuevo (9 de enero de 1658) se hace eco de una noticia según la cual Cristina impulsa rebeliones en Nápoles y se dispone a invadirlo con ayuda de ingleses y franceses (II: 151), dando «calor y ayuda a los malcontentos de aquel reino» (II: 156).

Al cambio de las circunstancias, con la inclinación francesa de la reina y la separación de los intereses españoles, atribuye Barrionuevo la prohibición del auto calderoniano La protestación de la fe:

Habiendo hecho don Pedro Calderón un auto sacramental de la reducción a la fe de la reina de Suecia bajó decreto del rey al presidente no se hiciese, porque las cosas de esta señora no estaban en aquel primer estado que tuvieron al principio, cuya casa y servicio de criados se compone ahora de solos franceses (I: 284).

Permítaseme un breve excurso sobre esta prohibición. El comentario de Barrionuevo ha marcado valoraciones posteriores del auto de Calderón, de manera que se suele considerar un panegírico de la reina que resultaría inoportuno en momentos de tensión política (Clavería, 1952: 23-24; Oostendorp, 1989: 259; Vásquez Lopera, 1998: 762; Oteiza, 2009: 434, n. 26; Andrachuck, 2001: 14, 21...). Sin duda la razón de prohibirse es el cambio de circunstancias, pero eso no hace del auto calderoniano un panegírico en la línea de otros textos literarios antes comentados. Cuando escribe Barrionuevo no puede conocer el texto del auto: supone plausiblemente las razones, pero no dice - ni

${ }^{10}$ Sobre las ambiciones de Cristina relativas a Flandes y Nápoles véase Allendesalazar (2009: 208, 252-253, 281-368). 
puede decir - que el rey quería impedir los excesivos elogios a la reina de Suecia. En realidad el auto no parece muy diplomático: la escena de la abjuración, por ejemplo, es terrible y la autoinculpación de la reina, con su nombre preciso, no parece atenida a ninguna discreción de cortesía ${ }^{11}$ :

Yo, Cristina Adolfo, Reina

de Suecia y Gocia, rama

de aquel generoso tronco

que siglos y edades largas

dio tantos héroes al mundo,

y tantos reyes a España,

cuyas cenizas conservan

hasta hoy Recisundo y Vamba

yo, Cristina Adolfo, que

delincuente voluntaria

presente parezco ante

tu justicia soberana,

para sentarme más digna

a tu mesa con la blanca

veste que la Penitencia

para mi persona guarda:

primeramente delato

de mí misma, en confianza

de que tu misericordia

piadosamente me valga,

y confieso convencida

en la criminal probanza

que el fiscal de mi conciencia

conclusa tiene en mi causa,

que es verdad que, miserable,

incurrí con ignorancia

en el heredado error

de Lutero, cuya falsa

doctrina seguí los años

de mi edad, y dando gracias

al cielo de que me diese

la luz verdadera y clara

de su Religión, que es

la Católica Romana,

abjuro, anatematizo,

y detesto mi pasada

vida y religión, jurando

vehementemente dejarla;

y no sólo no volver

a sus ceguedades vanas

en público ni en secreto, mas, sometida a la Sacra

Sede Apostólica, y

\footnotetext{
${ }^{11}$ Cito por la edición de Andrachuck (Calderón de la Barca, 2001).
} 


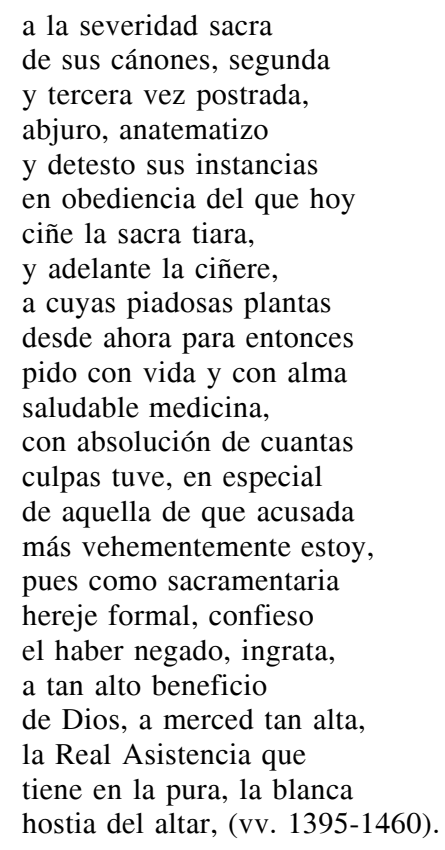

Otros pasajes son igualmente comprometidos, sobre todo el ofrecimiento de un reino que le hace el rey del auto:

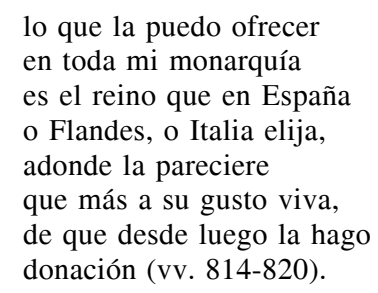

Texto que resultaría sumamente inoportuno cuando Cristina estaba pretendiendo Flandes o Nápoles, y no entraba tal cosa en los cálculos del rey.

Hacer de Cristina la protagonista de un auto no convenía, en efecto, aunque no hubiese en él la gran exaltación que los estudiosos han visto, a mi juicio sin motivo suficiente, en la obra.

Sea como fuere, las noticias de desavenencias y actitudes antiespañolas se acumulan y Barrionuevo las atribuyen a menudo, con misógino desprecio, a la volubilidad femenina:

la reina de Suecia queda muy agasajada del francés. Ella lo quiere ver todo. Es mujer; no me espanta (II: 8) [...] Dícese que la reina de Suecia se ha vuelto a Roma. Espíritu ambulativo tiene esta señora. No me espanta, que es mujer (II: 12). 
Un episodio notable con ribetes de escándalo es la ruptura con Pimentel, favorito un tiempo de la reina y según rumores extendidos, su amante (López Cordón, 2004: 58, 62..., Villaurrutia, 1962: 29 y ss.; Allendesalazar, 2009: 195$196,285 \ldots$ ): la reina lo echa de su lado con maneras violentas e indecorosas —era su costumbre, al parecer, usar cuando se enojaba un lenguaje vulgar-, y según Barrionuevo, que reproduce en estilo directo la filípica de la reina, le dijo: «Sois un pícaro gallina, ladrón, infame y mal caballero» (I: 295-296). Otro más serio es la muerte de Monaldesco ${ }^{12}$, que Barrionuevo atribuye al despecho de la reina por acusarle aquel de «echarse» con el rey de Francia o bien por descubrir sus conjuras en el asunto de Nápoles. El cronista destaca la crueldad del asesinato («haciendo [..] matar a puñaladas en presencia suya a un caballerizo», II: 151), acción que provoca gran resentimiento en el papa, pues Monaldeschi estaba «muy emparentado en Roma» (II: 158).

Pero Cristina no parece impresionarse. Acciones escandalosas y extravagantes empiezan a marcar la deriva de la reina.

Ya en territorios de franca degeneración, con no disimulada complacencia notifica Barrionuevo la aparición de un pasquín (Allensalazar, 2009: 296) en el que imputan a Cristina amoríos con Pimentel y un cardenal:

Pusieron a la reina de Suecia un pasquín muy bellaco, tratándola de hipócrita, vana, loca y deshonesta con don Antonio Pimentel, su querido del alma, y otros y se dice que un cardenal le dio una joya riquísima (I: 277).

No muestra el avisador muchas dificultades para dar pábulo a estas y otras acusaciones. Quizá una de las más duras sea la que recoge en la carta de 30 de agosto de 1656, sobre un embarazo que habría debido a un cardenal —quizá el mismo aludido en la cita anterior-, al que llama Lomelin:

Dícese que la reina de Suecia se salió tan presto de Roma por hallarse embarazada de un cardenal que la festejaba y que estando para ir a Francia [...] se detiene a desbuchar en Hamburgo [...] Es mujer: no me maravillaré que sea verdad (I: 306). [...] Dícese va embarazada de cuatro meses del cardenal Lomelin, mozo gallardo y de lindo talle y disposición. Si se le fue en Roma el pie no me maravillaré se haya asentado, que otras tan grandes señoras como ella lo han hecho (I: 312 ).

Sin duda se refiere esta hablilla que recoge con gusto a los amores, platónicos, según algunos historiadores; menos inocentes según otros, mantenidos con el cardenal Azzolino ${ }^{13}$.

Lo que me parece más relevante a efectos de la dicotomía persona/personaje es que este tipo de noticias quedan excluidas de los tratamientos literarios, mientras que definen en Barrionuevo la principal perspectiva con la que

\footnotetext{
${ }^{12}$ Véase Allendesalazar (2009: 338-339) sobre este episodio. El marqués de Monaldesco era caballerizo mayor de la reina, que lo acusa de traidor y lo hace matar.

${ }^{13}$ Allendesalazar (2009: 287 y ss., 375) y López Cordón (2004: 58, 62...) los consideran amores platónicos... Barrionuevo, desde luego, no compartiría esa visión.
} 
se evoca a Cristina. Semejante selección de motivos y enfoque de los comentarios no dejan de ser coherentes con el género textual de los avisos: en este caso, no solo las prerrogativas de la poesía permiten definir el tratamiento de los personajes históricos; los privilegios libérrimos del cotilleo adquieren un protagonismo especial, impulsado sin duda por una mirada misógina que podría ser propia del relator o debida a la tendencia satírica de la misma categoría textual.

Este enfoque permitiría centrar mejor las valoraciones sobre la misoginia del cronista, que Compte (2012) no acaba de situar en su contexto, sobre todo cuando aborda otra figura de reina, Mariana de Austria, cuyo papel, según la estudiosa, trivializaría Barrionuevo - aunque la trate con más respeto y deferencia que a Cristina- al convertirla en mera productora de un heredero:

This almost exclusive association of the Queen with either fanciful diversions or with childbearing aligned with capriciousness and indulgence further paints a picture of a trivialized queen. Her role as depicted in the Avisos is not just as royal childbearer, but to deliver a son (Compte, 2012: 207) ${ }^{14}$.

Cabe señalar que proporcionar un heredero a la monarquía española no es cuestión baladí, sino que implica una perspectiva política global que afectaba a millones de personas. En otra medida la conversión de Cristina podría haber tenido consecuencias políticas muy notables: lo que a Barrionuevo le escama es el aspecto exhibicionista de la reina sueca, que le parece sospechoso y de poca seriedad, propio de una persona desequilibrada. Y en el marco de los avisos esta perspectiva se traduce en un tono irónico, satírico, burlesco en ocasiones.

Para examinar los modos en los que una persona histórica se transmuta en personaje con dimensiones de ficción o mito, conviene, pues, observar no solo los géneros en los que la Poesía enmienda a la Historia, como dice Bances Candamo, sino aquellos otros en los que la sabrosa y malvada murmuración, gracias a los mecanismos textuales pertinentes, contribuye a cargar las tintas sobre las máscaras que tantas veces acaban sustituyendo al rostro.

${ }^{14}$ Algo forzada es la interpretación de las referencias de Barrionuevo a las diversiones de la reina Mariana y a su afición al teatro. El aficionado era el rey y Barrionuevo al criticar los dispendios denuncia al rey sobre todo, y privados, no a la reina. Tampoco creo que la misoginia de Barrionuevo sea tan profunda como para atribuir la perdición de España a las mujeres. Este enfoque prescinde del resto de las observaciones de Barrionuevo sobre los personajes masculinos. La misoginia no es una clave exclusiva de lectura, sino un componente más de las observaciones satíricas del avisador, y precisamente por integrarse en las convenciones de un género literario, reflejaría menos que otros comentarios una posición personal. Compte, por cierto, parece consciente de esta circunstancia, aunque a mi juicio no la tiene muy en cuenta en sus conclusiones ( $«$ His criticism in this regard is not limited by gender, as he occasionally reproves the King's costly hunting retreats and palace entertainments», Compte, 2012: 206). 


\section{BIBLIOGRAFÍA CITADA}

Allendesalazar, Úrsula de (2009). La reina Cristina de Suecia. Madrid: Marcial Pons.

Andrachuck, Gregoty Peter (2001). «Introducción», en Pedro Calderón de la Barca, La protestación de la fe. Peter G. Andrachuck (ed.). Kassel: Reichenberger.

Arellano, Ignacio (1998). «Teoría y práctica de los géneros dramáticos en Bances Candamo», en Christoph Strosetzki (ed.), Studia Hispanica. Teatro español del Siglo de Oro. Teoría y práctica, Madrid-Frankfurt: Iberoamericana-Vervuert, pp. 1-26.

Barrionuevo, Jerónimo (1968). Avisos (1654-1658). Antonio Paz y Mélia (ed.). Madrid: Atlas, 2 vols.

Calderón de la Barca, Pedro (2001). La protestación de la fe. Peter G. Andrachuck (ed.). Kassel: Reichenberger

Clavería, Carlos (1952). «Gustavo Adolfo y Cristina de Suecia, vistos por los españoles de su tiempo», Clavileño. 17, pp. 11-15; y 18, pp. 17-27.

Compte, Deborah (2012). «Damning Female Portraits: The Avisos of Jerónimo de Barrionuevo», Hispania. 95.2, pp. 201-210.

Escalonilla López, Rosa Ana (2005). «La historia moderna en Calderón: Afectos de odio y amor», en Carlos Mata y Miguel Zugasti (ed.), Actas del Congreso El Siglo de Oro en el Nuevo Milenio, I. Pamplona: EUNSA, pp. 647-658.

González Cañal, Rafael (1986). «El Conde de Rebolledo y la Reina Cristina de Suecia: una amistad olvidada», Revista Tierras de León. 62, pp. 93-108.

González Cañal, Rafael (1997). Edición crítica de los «Ocios» del Conde de Rebolledo, Cuenca: Ediciones de la Universidad de Castilla-La Mancha.

Lauer, Robert (1992). «La tragedia histórica del Siglo de Oro», Noesis. 8, pp. 25-37.

López Cordón, María Victoria (2004). «Minerva del Norte», La aventura de la Historia. 64, pp. 56-62.

Lundelius, Ruth (1986). "Queen Christina of Sweden and Calderón's Afectos de Odio y Amor», Bulletin of the Comediantes. 38.2, pp. 231-248.

Mackenzie, Ann L. (1979). «Dos comedias tratando de la reina Cristina de Suecia: Afectos de odio y amor por Calderón y Quién es quien premia al amor por Bances Candamo», en H. Flasche, K. H. Körner, y H. Mattauch (ed.), Hacia Calderón (IV Coloquio Anglogermano, Wolfenbüttel, 1975). Berlin-New York: Walter de Gruyter, pp. 56-70.

Maler, Bertil (1978). «La sucesión de Carlos II y la corte de Suecia», Boletín de la Real Academia Española. 58, pp. 159-168.

Mancini, Matteo (2003). «La corte de Cristina de Suecia en Roma», en Cortes del Barroco. De Bernini y Velázquez a Luca Giordano. Madrid: SEACEX, pp. 242-259.

Oostendorp, Henk (1989). «Cristina de Suecia en el teatro español del siglo XVII», Diálogos hispánicos de Amsterdam. 8/II, pp. 245-59.

Oteiza, Blanca (2009). «Hipótesis de una escritura: ¿Quién es quien premia al amor?, de Bances», en Ars bene docendi. Homenaje al profesor Kurt Spang. Pamplona: EUNSA, pp. 433-442.

Prieto, María Remedios (1978-1980). «Documentos relativos al auto sacramental de Calderón La protestación de la Fe», Segismundo. 14, pp. 195-216.

Suárez Miramón, Ana (1992). «Bances Candamo: Hacia un teatro ilustrado y polémico», Revista de Literatura. 55.109, pp. 5-54.

Vásquez Lopera, Julián (1998). «Bajo el signo de la diplomacia. La reina Cristina en la literatura del Siglo de Oro: del conde Bernardino de Rebolledo a Calderón y Bances Candamo», en E. Martínez Ruiz y M. de Pazzis Pi Corrales (dir.), España y Suecia en la época del Barroco (1600-1660). Actas del Congreso Internacional. Madrid: Comunidad Autónoma de Madrid, Consejería de Educación y Cultura, pp. 761-791.

Villaurrutia, Marqués de (1962). Cristina de Suecia. Madrid: Espasa Calpe. 
Weiner, Jack (1979). «Cristina de Suecia en dos obras de Calderón de la Barca», Bulletin of the Comediantes. 31, pp. 25-31.

Zúñiga, Ana (2012). «Dilema entre poder y religión. La figura de Cristina de Suecia, mujer varonil, erudita y esquiva», Theatralia. 14, pp. 147-159.

Fecha de recepción: 27 de enero de 2014.

Fecha de aceptación: 28 de mayo de 2014. 